\title{
A construção do significado de controle social com conselheiros de saúde no Estado do Piauí, Brasil
}

\author{
Construction of meanings relating to social control \\ with health counselors in Piauí state, Brazil
}

José I vo dos Santos Pedrosa 1

\footnotetext{
1 Núcleo de Estudos de Saúde Pública, Centro de Ciências da Saúde, Universidade Federal do Piauí. Av. Frei Serafim 2280, Teresina, PI 64000-010, Brasil.
}

\begin{abstract}
This article describes a health education experiment with health counsel ors in two health administration districts in the State of Piaui, Brazil. Focusing on the Ministry of Health's Project for Social Control and People's Participation in Health, the article analyzes forms and contents pertaining to the issue of social control in the health field, under a situation where society is controlled by small groups detaining both power and wealth. The experiment showed the importance of constructing meanings concerning social control in day-to-day relationships between the community and health services and the strategic role of health professionals in developing health education activities.

Key words Health Services; Health Education; Health Planning Councils

Resumo Descrição de uma experiência de intervenção pedagógica junto aos consel hei ros de saúde de duas Diretorias Regionais de Saúde do Estado do Piauí. Valendo-se do projeto de Incentivo ao Controle Social eà Participação Popular na Construção do SUS, do Ministério da Saúde, o artigo analisa as formas e conteú dos da questão do controle social em saúde, numa si tuação em que o controle político e econômi co da sociedade é exercido por pequenos grupos donos do poder e da riqueza, que configuram o padrão ol igárquico de dominação. Neste senti do, a experiência demonstrou a importância da construção coletiva do significado de controle social com bases nas relações coti di anas entre a comuni dade e os serviços de saúde e o papel estratégi co do profissional ao desenvolver estas ações.

Palavras-chave Serviços de Saúde; Educação em Saúde; Consel ho de Planejamento em Saúde
\end{abstract}




\section{Introdução}

O Projeto de Incentivo ao Controle Social e à Participação na Construção do SUS resulta da parceria entre o Ministério da Saúde, a Coordenação de Informação, Educação e Comunicação do Projeto Nordeste, a Universidade de Brasília e as Universidades do Nordeste, objetivando capacitar consel heiros de saúde, lideranças comunitárias, técnicos dos serviços e das secretarias executivas dos Consel hos de Saúde, difundindo informações sobre: financiamento, legislação, organização dos serviços e dados epidemiológicos.

No Piauí, foram realizados seminários nas 17 Diretorias Regionais de Saúde, onde se discutiam: o controle social e a descentralização do SUS, o financiamento do setor, informações e planejamento em saúde e a Norma Operacional Básica do Ministério da Saúde de orientação para a municipalização. Nestes seminários, cada tema tem sido trabalhado com base em exposições dialogadas, discussões em grupos e leituras das cartilhas instrucionais.

O material instrucional consta de duas cartilhas: uma, mais acadêmica, dirigida aos monitores, e outra, numa linguagem mais comum e utilizando mais recursos gráficos, dirigida aos conselheiros.

Em relação ao tema - o controle social na construção do SUS-, este material define controle social "como o processo no qual a população participa, através de representantes, na de finição, execução e acompanhamento das políticas públicas, as políticas do governo" (MS, 1994); aponta as Conferências e as Plenárias como mecanismos de o Município discutir seus problemas, "éo momento de consulta ampliada à sociedade (...) [quando] o que é mais importanteéo que se discute em cada município, em cada localidade" (MS, 1994).

Ressalta ainda o papel do cidadão numa relação de "direi tos e deveres com o Estado" (MS, 1994). Neste quadro, o Consel ho de Saúde "éa mais pura forma de democracia", onde convivem o Secretário de Saúde e os representantes dos setores da sociedade civil. Para tanto torna-se necessária a "legiti mi dade de seus membros" e "a paridadeem sua constituição" (MS, 1994).

A minha participação no Projeto, como monitor responsável pela apresentação do tema em foco, teve como referência o entendimento de participação enquanto intervenção, no sentido discutido no campo da análise institucional; intervenção que não se separa da análise e que significa uma ação decorrente da dialética que ocorre nas dimensões da realidade cotidia- na, no nível dos grupos, das organizações - "nível dos aparel hos, de ligações, de transmissão de ordens, da organização, da burocracia" (Lapassade, 1979) - e no nível “do jurídico, político, o Estado" (Lapassade, 1979).

Dessa forma, a participação teve por base tanto a análise político-institucional do processo que fez com que o evento fosse realizado naquele momento e lugar, quanto a intervenção nos elementos que se fizeram presentes às discussões, no sentido de captá-los e organizálos para uma ação futura a ser realizada em direção à realidade, na qual se inseria o grupo de conselheiros.

A participação voltada para estes objetivos define uma situação de análise, isto é, uma interação entre elementos diversos que "está estreitamente determinada pela presença física dos analistas enquanto atores sociai s em uma situação social epela presença material de todo contexto institucional" (Lourau, 1975).

A situação de análise que se configurou, tendo por um lado o material instrucional a ser utilizado e por outro lado a realidade das forças sociais presentes na sociedade piauiense, fez surgirem duas questões que contribuíram para esta reflexão: a primeira diz respeito à forma em que os conteúdos são apresentados seminários -, e a segunda diz respeito ao conteúdo da discussão, centrado em conceitos fundamentais como democracia, cidadania, legitimidade. Tais palavras não fazem parte do universo lingüístico da população piauiense, exposta ao padrão oligárquico de dominação, ou seja, a uma contínua reprodução de relações de dominação, cujas raízes históricas remontam à concentração de terra e de poder pela oligarquia rural, que manifesta-se atualmente em relações sociais que ultrapassam a dominação econômica, política e cultural por parte dos grupos hegemônicos e reflete na maneira de ser, de agir e de se organizar, por parte dos grupos excluídos.

Após breves considerações sobre estes pontos, apresento uma proposta de desenvolvimento para o tema, com base na experiência de seminários realizados em duas Diretorias Regionais de Saúde, instâncias descentralizadas da gestão do Estado no setor saúde.

\section{A questão da forma}

Segundo o Dicionário Aurélio (Ferreira, 1975), seminário é um grupo de estudos em que se debate a matéria exposta por cada participante. Pressupõe, portanto, que o grupo tenha definido uma matéria com a qual os integrantes 
se identifiquem e sobre a qual cada participante detenha um posicionamento, uma informação, um conhecimento.

O processo de institucionalização do SUS no Estado do Piauí não escapa aos efeitos do padrão oligárquico de dominação, o qual, em seu movimento de reprodução e manutenção do poder, institucionaliza práticas políticas tradicionais como o clientelismo, o fisiologismo, a opacidade em torno de seus projetos etc. A título de exemplo, o processo de constituição dos consel hos municipais de saúde representa, em sua grande maioria, a extensão do poder executivo a este espaço, que passa a ser ocupado pelos amigos do prefeito.

Dessa forma, entre os indivíduos que compõem o grupo de conselheiros para o qual destina-se o seminário não há um posicionamento sobre o significado que tal espaço representa na situação em questão. Ou melhor, o significado que o conselho tem para cada um dos representantes ali reunidos é a representação que cada um tem sobre este tipo de prática organizacional, geralmente calcada em experiências anteriores, em vivências particulares. Assim, não é estranho que os amigos do prefeito tenham do Conselho a idéia de extensão do executivo, os funcionários o vejam como local de disputa entre o estado patrão e o empregado, os produtores privados, como um empeciIho à livre iniciativa.

Além disso, as experiências anteriores de participação na organização do setor saúde remontam a três situações: a) para as instituições, a existência da Comissão Interinstitucional Municipal de Saúde - CIMS -, na década de 80, não passou de mera formalidade, resultando numa experiência que não aconteceu; $b$ ) para a população efetivamente engajada em movimentos de contestação/ reivindicação dirigidos geralmente contra o governo, a participação não ultrapassou este nível e c) para a população em geral, não houve reconhecimento de qualquer alteração na organização do sistema, a não ser naquelas ligadas diretamente ao acesso aos serviços.

Em termos coletivos, pode-se dizer que o conselho é um espaço desconhecido, como são desconhecidos, de forma análoga, os rumos de uma sociedade ao redemocratizar-se.

Diante disso, o seminário deve representar o espaço onde é possível revelar o desconhecido, deve tornar visível num horizonte temporal as possibilidades de realização dos desejos coletivos que as pessoas ali reunidas apresentam. Assim, a situação na qual irão envolver-se conselheiros e monitores é aquela onde há um trabalho de desvelamento, de revelação.
Entretanto, este processo de revelação tem origem, num primeiro momento, no próprio caráter instituído do Consel ho: instância deliberativa da política de saúde, promulgada através de lei, o que implica que a revelação tem uma direcionalidade que é dada pela Coordenação do Projeto, qual seja, a ousadia de fazer cumprir a lei deve ser seguida. Este aspecto aponta o papel do monitor como um indivíduo que participa do seminário, mas que apresenta uma diferente situação em relação aos outros participantes.

A este monitor é atribuído o papel de condutor do grupo, reconhecido pelos participantes, aquele que detém mais informações sobre o tema e que se identifica a uma instituição. Nesta situação, além do papel instituído, o monitor também serve de elemento através do qual o grupo se identifica; em algumas situações onde o Conselho nunca se reuniu, o monitor também serve de acontecimento, de desencadeador de fatos inéditos.

Neste sentido, a forma seminário não me parece ser a nomenclatura mais adequada para uma prática pedagógica onde a figura do monitor tem um papel de relevância. Tal prática está muita mais próxima da figura do animador, de que trata Campos (1994), para quem, “... animadores eapoiadores deste processo, que tanto podem ser um governo recém-el eito, como a direção de uma instituição, ou parcelas dos trabalhadores da base, ou segmentos politizados de usuários".

Enquanto prática pedagógica, L'Abbate (1994) chama atenção para duas características fundamentais dos profissionais de saúde envolvidos em atividades desta natureza: o 'verniz' teórico e ideológico do profissional e o desejo de 'sentir-se' sujeito, o qual é entendido como "uma pessoa em busca de autonomia, disposta a correr riscos, abrir-se ao novo, ao desconhecido, ena perspectiva deser al guém que vive numa sociedade determinada, capaz de perceber seu papel pessoal/profissional/social diante dos desafi os colocados a cada momento".

Diante destas considerações, o encontro com os consel heiros está mais adequado ao caráter de oficina, "que se constitui espaço para reflexão e discussão das vivências, permitindo a identificação de temas fundamentais para meIhor compreender o problema em pauta (...) a possi bilidade de conjugar a refl exão e ação, facilitar o emergir dos conheci mentos ou das representações (...) acerca da temática ..."(Chiesa $\&$ Westhpal, 1995). 


\section{A questão do conteúdo}

A Constituição Brasileira, outorgada em 1988, da qual emergem as leis que definem o Sistema Ú nico de Saúde, estruturado na existência de conselhos nos três níveis de gestão, tem como base a representação de um vir a ser ainda não presente na realidade cotidiana. Um vir a ser objetivado numa determinada visão de mundo, a qual, mediante certos mecanismos, é instituída como a Política Nacional de Saúde, definindo espaços, atores, ações.

A construção dessa visão de mundo e o seu reconhecimento como sendo a realidade é um processo que depende de dois fatores: como o sujeito concebe o mundo no qual atua e como se posiciona diante desse mundo cheio de conflitos e possibilidades.

Faz parte das estratégias do grupo político no poder sob o padrão oligárquico de dominação a inexistência de práticas institucionais solidárias, coletivas e democráticas. Os vários projetos sociais que preconizam estratégias participativas acabam tendo suas ações subordinadas à lógica que reina nas organizações da burocracia pública que gerenciam tais projetos.

O regime democrático instituído no País define novas arenas de debates políticos acerca de projetos apresentados pelos atores sociais. Entretanto, isto não quer dizer que, ao definir uma arena, todos os contendedores estejam armados com os mesmos instrumentos. Os atores sociais, quando penetram nas arenas, não estão em iguais condições. A estas condições pode-se chamar de recursos de poder (Testa, 1992).

Neste sentido, Democracia, Controle Social, Representati vidade, Paridade, Legitimidade, são palavras que fazem parte do vocabulário de alguns, dos 'políticos', dos 'doutores', e mesmo dos membros do MOPS e do PT, isto é, de atores externos aos consel hos. Neste caso, a experiência e o conhecimento destes conceitos por alguns conselheiros presentes nos seminários passam a representar os recursos positivos por parte de quem os detém.

Assim, não há como identificar o espaço do encontro como sendo o espaço da democracia definido na cartilha. Também não há como identificar os consel heiros como legítimos representantes de forças sociais que não Ihes reconhecem como tais, e, muito menos, considerá-los sujeitos participantes que utilizam este espaço para construir sua autonomia e a daqueles que representam.

Em outras palavras, os conceitos centrais deverão ser construídos a partir das vivên- cias/ representações/ conhecimentos de cada elemento do grupo, e o monitor será o condutor deste processo de construção. Ao monitor cabe a tarefa de garimpar nestas experiências a matéria prima essencial para a construção de uma representação social do conselho como espaço coletivo, onde as relações sejam democráticas, ou seja, onde exista igualdade de participação.

Estes pontos servem de base para a intervenção. No entanto, pelas características do projeto em si e sua significação no momento de consolidação do controle social no SUS, a intervenção é precedida por uma análise, a qual orienta a intervenção.

\section{A análise}

Os Conselhos de Saúde e o próprio Projeto de Incentivo ao Controle Social no SUS mostram aspectos instituídos e instituintes presentes no projeto político de desenvolvimento da cidadania, porquanto, mesmo incorporado à estrutura organizacional do setor saúde por parte do Estado, por meio de instrumentos jurídicos e burocráticos, dependem de práticas criativas e transformadoras que só podem ocorrer entre sujeitos (L'Abbate, 1994).

A intervenção proposta dirige-se ao universo de um possível vir a ser, isto é, às práticas dos consel heiros de saúde, ocupando um espaço que tem o poder de deliberar sobre as ações que compõem a política de saúde de um determinado município. Isto implica reconhecer as necessidades como direitos dos cidadãos e como demandas colocadas aos serviços de saúde.

Por outro lado, o universo instituído tem suas regras; regras que definem normas de escalonamento de acesso ao poder decisório, que devem ser do conhecimento e reconhecimento de todos os envolvidos, demarcando o campo das relações burocráticas como sendo o campo de racionalização e neutralização dos conflitos. Todavia, a natureza e os limites da intervenção definem-se no aspecto instituinte.

Para colocar numa relação dialética as dicotomias que aparentemente estão presentes na relação entre o instituinte/instituído, monitor/conselheiros, análise/intervenção, tomo como referência a proposta analítica de Lapassade (1979), na qual utiliza o conceito de analisador.

Este autor descreve o significado de analisador em vários campos, na química, na psicologia pavloviana, na psicanálise freudiana e na análise institucional. Neste campo, toma para 
analisador, a definição dada por Lourau (1975), segundo a qual analisador é o "que permite re velar a estrutura da instituição, provocá-la, obrigá-la a falar". Este ato de fala, base para a intervenção na instituição, por ser resultado de uma provocação, "exigea mediação de indivíduos particulares aquel es que por sua situação dentro da organização leva à singulari dade de 'provocadores'" (Lourau, 1975).

Lapassade define ainda: a) os analisadores naturais, aqueles que se impõem por si mesmos à instituição, como uma greve, uma revolução, e b) os analisadores construídos pelo analista com o intuito de análise.

a) São analisadores naturais: a situação da dominação oligárquica que se torna evidente no Piauí, a vinculação institucional do Projeto de Incentivo ao Controle Social no SUS e o monitor como provocador.

A situação da dominação oligárquica implica considerar a questão da representatividade dos segmentos envolvidos no setor. As organizações populares e sindicais, em sua grande maioria, acabam surgindo como espaços estratégicos de legitimação de atores particulares, ou são consolidadas momentaneamente em movimentos de lutas pontuais contra o Estado. As associações de profissionais caracterizamse pelo teor corporativo e pela susceptibilidade à cooptação, enquanto os representantes do poder público mostram-se como representantes de famílias, grupos políticos, partidos etc. Tal analisador põe em evidência a necessidade de revelar os elementos estruturais do processo (leis, regimentos, estatutos etc.) que, além de contribuírem para o aspecto legítimo da dominação, também asseguram a participação.

A vinculação institucional do Projeto com o Ministério da Saúde e com o Programa das Nações Unidas para o Desenvolvimento - PNUD - exige o cumprimento de metas, de recursos financeiros, de contrapartidas. A vinculação do projeto com as Universidades e com os Núcleos de Estudos de Saúde Pública/ Coletiva expõe o compromisso com o SUS constitucional. Tal compromisso define o caráter da implementação da proposta e revela a necessidade de construir os conceitos a partir da vivência dos grupos em suas relações com o cotidiano.

O monitor enquanto provocador é o analisador que aponta o caráter da intervenção. Lapassade (1979) define três tipos de provocadores: ideológico, aquele que emite dúvidas sobre as finalidades e estratégi as gerais da organização; libidinal, o que ocupa um imenso lugar dentro da estrutura libidinal do grupo e apenas com sua presença deixa dúvidas a respeito da seriedade da ideologia e da organização e or- ganizativo, aquele que ataca de frente os problemas mais práticos e materiais contidos na organização.

b) Como analisador construído, tem-se a abordagem do tema.

Os analisadores utilizados indicam que a abordagem do tema, enquanto processo, ela mesma, de revelação da instituição que existe na questão do controle social, deve considerar que:

1) a concentração do poder político nas mãos dos mesmos grupos dominantes no Piauí não é uma questão da natureza; insere-se no processo de luta pela hegemonia da condução política da sociedade piauiense;

2) as estratégias para a dominação e o controle político encontram-se presentes em todos os espaços da vida social: nas relações de trabaIho, no acesso à cultura, ao lazer, à escola, nos movimentos do jogo eleitoral, no acesso ao funcionalismo público etc.;

3) o espaço do consel ho deve mostrar-se como um espaço de transparência, onde cada pessoa expressa o que é, o que representa, quais seus interesses, ao mesmo tempo que escuta e reconhece a presença de outros com outros interesses;

4) para participar deste espaço e desenvolver ações que realizem os interesses da coletividade, é imprescindível que cada pessoa reconheça a si mesma e ao outro por meio do conhecimento das igualdades e diferenças que existem numa relação entre sujeitos que buscam autonomia;

5) o caráter instituído do conselho transforma-o numa arena, onde os participantes entram em cena com os recursos de poder de que dispõem;

6) as informações sobre os aspectos normativos e legais do Conselho, sobre o estado sanitário da população, a participação no planejamento, são os instrumentos que direcionam a institucionalização do Conselho como espaço democrático e participativo.

\section{A intervenção (a proposta)}

Diante destas considerações, desenvolveu-se o tema em duas Regionais de Saúde, utilizando a metodologia descrita. O monitor, mediante figuras feitas com papel madeira e pincel atômico, apresentava palavras que se iam relacionando umas às outras, à medida que os participantes iam relatando situações vivenciadas por cada um.

A seqüência na qual os seis quadros foram apresentados obedeceu a duas lógicas: uma, 
referente à análise, era relacionada ao conteúdo, isto é, ao significado do controle social em saúde no contexto local, e outra, pautada nas características da intervenção do monitor. A discussão a respeito do significado de controle social teve como ponto de partida as diferenças evidenciadas nas relações entre o cidadão e o Estado num regime democrático e num regime autoritário, como suporte para que a construção do significado de controle social tivesse como eixo as ações de reconhecimento do outro e a potencialidade das ações coletivas.

A intervenção do monitor consistiu em evidenciar para o grupo, por meio da fala dos participantes, as possibilidades de ação para o Conselho Municipal, devolvendo para o primeiro a discussão de sua viabilidade.

Os quatro primeiros quadros ajudavam a colocar em visibilidade as relações autoritárias vivenciadas no cotidiano das pessoas, na atuação dos políticos e do governo. Diante do desvelamento das relações de poder, o monitor fazia uma intervenção ideológica, pois colocava sempre em relação o 'dito e o feito', questionando a democracia dos discursos e as diferenciações observadas no cotidiano.

O primeiro quadro continha as palavras “Nós, Estado e Sociedade", que suscitaram reflexões sobre o governo autoritário, no qual a população reconhece o Estado como sendo o mundo das Leis, das Repartições, dos Políticos e dos Funcionários, e o Estado reconhece a população como Povo e Eleitor. No segundo quadro, as palavras apresentadas foram "Nós, Estado e Governo". As discussões que se seguiram apontaram que, para os participantes, o Estado se apossava do Governo e tratava o Nós como se fosse diferente, enquanto o Governo tratava bem seus I guais. O terceiro quadro apresentava uma interrogação: “ Onde a gente se reconhece como iguais?", diante da qual os presentes expressaram a vivência do reconhecimento do outro na Casa, na Família, na Rua, no Bairro, na Cidade, no Trabalho e no Lazer. Também se reconheciam como iguais nas Condições de Vida, principalmente nas Condições de Saúde e de Educação.

No quarto quadro, ainda discutindo as ambigüidades presentes na situação, foi apresentada outra interrogação: "Como a gente se reconhece como iguais?" Tal interrogação suscitou o debate a respeito das formas de reconhecimento do outro nos processos de sociabilidade, que ocorrem por meio Daquilo que a Gente Sente na Gente Mesmo, que tem origem nas Necessidades, Daquilo que a Gente Reconhece que Sente, que está relacionado aos Direitos Sociais, bem como por intermédio Do que a
Gente Gostaria de Sentir, que é o Nosso Projeto de Vida em Construção.

A partir da apresentação do quinto quadro, houve um predomínio do momento da intervenção, em que a ação do monitor objetiva não somente a identificação dos elementos que permeiam a situação - o controle social proposto para o SUS e o controle político local, como também uma intervenção que busca suscitar possibilidades e dúvidas a respeito da ação do grupo, em que o monitor atua a fim de:

- desafiar o grupo a ser capaz de diferenciar entre o que o indivíduo sente e o que dizem que ele sente e, ao mesmo tempo, tentar organizar a dicotomia em torno da Informação em Saúde - o que É, quem Produz, como Circula e qual É sua Leitura;

- desafiar o grupo a aceitar os direitos dos diferentes através do Reconhecimento;

- desafiar o grupo a construir um projeto convivendo num mundo onde existem aqueles que estão ao nosso lado e aqueles que estão do outro lado.

Na seqüência, o que representou um momento de síntese, o monitor deixa de ser 'a intervenção', volta a mostrar-se como moderador entre a fala das pessoas, para captar o sentido que o grupo atribui ao controle social.

Assim, para as duas Regionais de Saúde, o sexto quadro representou a tradução do que ficou definido como sendo o controle social. Tal definição continha dois momentos: o primeiro definia o controle social como sendo a ação que transforma Necessidades em Direitos, que passam a se expressar de forma a ter Resposta Adequada. O segundo dizia respeito ao controle social como a ação que devia voltar-se para a construção do Plano Municipal. O significado de controle social construído na oficina levou a que o Plano fosse considerado um elemento que faz parte da transformação das Necessidades em possíveis Respostas e Instrumento para a Vigilância à Saúde, que é a ação do conseIheiro.

Como resultado da apresentação do tema para os três segmentos (usuários, prestadores e trabalhadores de saúde) representados no Consel ho Municipal de Saúde, na perspectiva da análise institucional, foi possível perceber que a ação dos conselheiros (agora vislumbrada como possível) mostrou homogeneidade e consenso no que diz respeito à adesão ao projeto de controle social no plano da universalidade dos direitos sociais. Entretanto, quando esta ação possível era relacionada ao momento da particularidade da política de saúde em curso no Piauí, cada segmento apresentou um posicionamento diferenciado, os usuários não re- 
conheciam os trabalhadores de saúde como aliados, que, por sua vez, buscavam alianças junto ao poder institucional, o qual, por manipular recursos de poder como a informação, as finanças e a burocracia, vislumbrava uma intervenção que dependia da negociação com os outros dois segmentos.

No plano da singularidade da ação possível por parte de cada indivíduo no interior do segmento ao qual pertencia, tornou-se evidente a unanimidade em torno do desejo de participar, seja nas organizações e movimentos sociais, seja nas discussões a respeito de trabalho e salário nos ambientes profissionais, ou ainda, na redistribuição do poder nas organizações do setor público.

Dessa forma, ao utilizar a apresentação do tema como um analisador da situação em cada uma das Regionais de Saúde, evidenciando a dinâmica dos indivíduos presentes como elemento do processo de institucionalização do controle social, o monitor e o grupo de conseIheiros definiram estratégias para a atuação da Coordenação do Projeto e, ao mesmo tempo, para o fortal ecimento dos Conselhos de Saúde no nível local.

Assim, na Regional onde predominou a presença de consel heiros representantes do poder público, trabalhadores de saúde e entidades não governamentais conduzidas pela I greja Católica (Pastorais da Saúde), a unidade nuclear básica na construção da definição do controle social foi o conceito de Coletivo como sendo o resultado das relações entre o que se tem em Comum e o que se mostra Diferente. Nesta Regional, o conceito de Movimento significou a ação do entendimento e da busca do consenso.

$\mathrm{Na}$ outra Regional, onde os conselheiros presentes em maior número eram os representantes dos usuários, com predominância de entidades não governamentais mais politizadas e onde o processo de municipalização tinha iniciado, a definição de controle social originou-se do conceito de Poder como sendo aquilo que é capaz de transformar as Necessidades em Direitos Reconhecidos. Nesta Regional, a noção de Movimento significou a ação de ter mais instrumentos para sentar à mesa de negociações com os outros segmentos envolvidos.

\section{Conclusões}

Com base na experiência realizada, ressalto como de suma importância para a prática de educação em saúde, em situações como a descrita, os seguintes pontos:

- A utilização de analisadores da situação de um momento de intervenção no processo de institucionalização do controle social em saúde contribui para a compreensão do significado desse processo por parte dos promotores da intervenção e por parte daqueles que nela são envolvidos. No caso relatado, também contribuiu para apontar a direção do que fazer por parte dos membros dos Consel hos de Saúde; se o movimento era dirigi do para a ampliação das bases de identificação e reconhecimento interno de cada segmento, ou se era dirigido para o reconhecimento externo de outros atores com os quais era necessário dialogar, negociar ou confrontar.

Quando a institucionalização do SUS compreende o momento de ampliação e adesão ao projeto instituinte, o conteúdo de tema controle social deve estar centrado na busca de identificação entre os indivíduos envolvidos na situação. Quando o momento do processo encontra-se no reconhecimento do Conselho como ator que participa da arena política da saúde, aquele conteúdo deve priorizar a discussão sobre os instrumentos a serem utilizados nos embates, como a informação, o planejamento participativo e a avaliação.

- A ação educativa deve ser desenvolvida com bases em metodologias e abordagens que levem à construção de significados dos temas em foco pelos grupos envolvidos (Método Paulo Freire, Psicodrama Pedagógico etc.). Ao mesmo tempo, a análise institucional do processo pode contribuir para a definição do controle social como uma ação em direção à construção do SUS constitucional.

O monitor, ao desenvolver sua intervenção pedagógica, deve observar a segmentarização do grupo em relação às questões levantadas e o grau de permeabilidade dos envolvidos a novas informações.

- O profissional envolvido deve estar munido destes recursos para que sua intervenção torne-se estratégica. 


\section{Referências}

CAMPOS, G. W. S., 1994. Considerações sobre a arte e a ciência da mudança: revolução das coisas e reformas das pessoas. O caso da saúde. In: Inventando a Mudança na Saúde(L. C. O. Cecílio, org.), pp. 29-87. São Paulo: Hucitec.

CHIESA, A. M. \&WESTPHAL, M. F., 1995. A sistematização de oficinas educativas problematizadoras no contexto dos serviços públicos de saúde. Saúdeem Debate, 46:19-22.

FERREIRA, A. B. H., 1975. Novo Dicionário da Língua Portuguesa. 1a ed., Rio de Janeiro: Nova Fronteira. L'ABBATE, S., 1994. Educação em saúde; uma nova abordagem. Cadernos de Saúde Pública, 10:481490.
LAPASSADE, G., 1979. El Analizador y el Analista. Barcelona: Gedisa.

LOURAU, R., 1975. Análise Institucional. Petrópolis: Vozes.

MS (Ministério da Saúde), 1994. Guia de Referências para o Controle Social (Manual de Conselheiros). Brasília: Coordenação de Informação, Educação e Comunicação/Núcleo de Estudos em Saúde Pública.

TESTA, M., 1992. Pensar em Saúde. Porto Alegre: Artes Médicas. 